AS I SEE IT*

\title{
Marine community ecology: importance of trait-mediated effects propagating through complex life cycles
}

\author{
Luis Giménez** \\ Sección Oceanología, Facultad de Ciencias, Igu 4225, 11400 Montevideo, Uruguay \\ Present address: Biologische Anstalt Helgoland, Alfred Wegener Institute for Polar and Marine Research, \\ 27498 Helgoland, Germany
}

\begin{abstract}
Present theory of marine community structure includes the effect of environmental factors that act upon larval survival on distribution and abundance of benthic adults. The theory assumes that pre-settlement environmental factors produce a direct effect at the population level, determining the abundance of individuals that enter the benthic habitat. These are density effects that propagate from the larval to the benthic phase (abbreviated here as DEMPHs). However, recent information suggests that pre-settlement factors may also produce an effect on population abundance, mediated by changes in traits of settlers. For instance, larvae experiencing food stress may give rise to juveniles with reduced energy reserves, growth rate, and in consequence with a low life expectancy. Thus, such trait-mediated (e.g. life historical, physiological) effects propagate through different life phases of the complex life cycles of benthic invertebrates, ultimately affecting juvenile survival. In this paper, I discuss the potential role of this special kind of trait-mediated effect (abbreviated here as DELPHIs) on benthic communities. I show that DELPHIs may affect the shape of the stock-settlement function leading to an erroneous interpretation of the role of post-settlement factors on benthic communities. Mortality due to DELPHIs is the consequence of pre-settlement factors but may be confounded with mortality due to post-settlement factors. In this regard, I conclude that the only solution to avoid this error is to incorporate measurements of traits of individuals in settlement and recruitment studies. Besides, DELPHIs may allow for complex interactions between pre- and post-settlement processes, suggesting that dichotomous views about the role of pre- and post-settlement processes are not appropriate. Finally, I suggest that future field research in benthic communities should incorporate an estimation of DELPHIs as a tool to expand, and thus improve, marine community theory.
\end{abstract}

KEY WORDS: Marine benthos $\cdot$ Delayed effects $\cdot$ Larvae $\cdot$ Settlement $\cdot$ Recruitment

\section{INTRODUCTION}

In species with complex life cycles (e.g. many marine invertebrates, fishes) the abundance of adult individuals is affected by abiotic (e.g. salinity) and biological (e.g. predation) processes acting on different life phases (eggs, larvae, juveniles, adults). If the phases do not share the same habitat (e.g. in benthic inverte- brates), there may be a distinct habitat- and sizedependent set of processes explaining the survival or growth rate at each phase. When the habitat is shared, size-dependent processes may still differentially affect the survival of individuals in different life phases. In marine benthic invertebrates, pelagic processes may act on the larval phase in the water column or at settlement; these factors include characteristics of the water 
column (e.g. larval transport: Roughgarden et al. 1988), or interactions between settling larvae and benthic adults (e.g. Peterson \& Black 1993). Benthic processes related to the substratum affect juveniles and adults (e.g. competition for space: Connell 1961). These factors are defined according to whether they occur before or after the settlement of larvae in the benthic habitat and the metamorphosis from larvae to juveniles; they are termed pre-settlement and postsettlement processes, respectively (Connell 1985, Jeffery 2003).

The development of an ecological theory that includes species with complex life cycles involves the solution of methodological problems concerning the measurement of the settlement rate, as well as a better understanding of how pre- and post-settlement processes affect populations and communities (see Roughgarden 1986, Menge 2000). Settlement is defined as the point when individuals first take permanent residence on the substratum (Keough \& Downes 1982, Connell 1985); it is a process that involves contact with the substratum, behavioural responses, and metamorphosis. However, most studies measure recruitment, which is the number of settlers surviving after a certain period of time in the benthos. Recruitment, the result of settlement plus early post-settlement mortality (Keough \& Downes 1982, Connell 1985), is an operational term that has been defined in different ways (Caley et al. 1996, Hunt \& Scheibling 1997). While settlement should be measured on a tidal or daily basis, recruitment may be measured on a weekly or monthly basis (Connell 1985, Raimondi 1990; see also discussions in Caley et al. 1996, Hunt \& Scheibling 1997, Pineda 2000, Paine 2002). Here, I focus on how preand post-settlement processes operate together. In particular, I discuss (1) 2 types of pre-settlement effects and (2) combined pre- and post-settlement effects on populations and communities. Although I focus on benthic invertebrates, many concepts discussed here are important for other marine groups such as benthic fishes (see McCormick 1998, McCormick \& Hoey 2004).

\section{DENSITY- AND TRAIT-MEDIATED EFFECTS IN COMPLEX LIFE CYCLES}

Pre-settlement processes include temperature, salinity, transport by currents, predation and food availability, all of which affect larval survival, growth, energy content, etc. They may be divided into 2 types: (1) those directly affecting the population through changes in the number of individuals that settle in the benthic habitat (density-mediated effects), and (2) those affecting the population through changes in traits of individual settlers (trait-mediated effects) that lead to changes in survival or reproduction. Both types of effects are propagated to the benthic phase since they affect either the abundance of juvenile stages or their growth or both.

Density-mediated effects that are propagated through different life phases (abbreviated as DEMPHs) are the ones most commonly studied in supply-side ecology (Connell 1985, Gaines \& Roughgarden 1985, Harms \& Anger 1989, Karlson \& Levitan 1990, Menge 2000). Roughgarden (1986) proposed a model of DEMPHs for benthic communities, focusing on sessile organisms of hard substrata: pre-settlement factors affected the strength of density-dependent post-settlement processes. In this model 3 different communities were distinguished: (1) At low settlement rates, a recruitment-limited community emerges where spacecompetition does not take place. At high settlement rates, the community will be space-limited, and structured by either (2) density-dependent mortality, which creates a patch mosaic of individuals of the same age classes and empty space, or (3) density-dependent growth, which gives rise to a lattice of tightly packed individuals. Further analyses (Menge \& Sutherland 1987, Connolly \& Roughgarden 2003) predicted that the strength of biological interactions depended on factors that govern the settlement rate. Some evidence has been provided by observations (Connolly \& Roughgarden 1998, Connolly et al. 2001) and experiments (Fairweather 1988, Robles 1997). However, other tests did not give unambiguous support to the model (Hyder et al. 1998, Menge 2000). Settlement and post-settlement factors may interact; if recruitment reflects settlement, that interaction explains why recruitment is necessary — but sometimes insufficient - for explaining adult population density (Menge 2000). In populations of soft sediment invertebrates competition after settlement need not lead to mortality (Wilson 1991, Peterson \& Black 1993), while larval supply does not seem to be a limiting factor (Olafsson et al. 1994, Hunt \& Scheibling 1997). However, these communities are affected by larval-adult interactions, with negative (Woodin 1976, André \& Rosenberg 1991) or positive (Highsmith 1982, Peterson \& Black 1993) effects of adults on larval settlement.

One assumption of the DEMPH models is that variability among individuals is not important to the pattern of survival of organisms. If trait-mediated effects propagate from the larval to the benthic phase and affect mortality, that assumption is violated since variability among individuals plays a role in explaining population patterns. Trait-mediated effects are all effects that involve the quality of an organism, resembling the trait-mediated indirect interactions (TMII) operating in a community (see Abrams 1995, Raimondi 
et al. 2000, Trussell et al. 2002, Werner \& Peacor 2003, Schmitz et al. 2004). They are truly delayed life-history (Beckerman et al. 2002), physiological (energy reserves, acclimation state), developmental (larval pathway) or other effects carried over to (cf. Pechenik et al. 1998) or propagating from one phase to the next in terms of changes in traits of individuals that may ultimately affect survival (abbreviated here as DELPHI). The inclusion of DELPHIs in the theory of communities involves a change in the view of how environmental factors affect larvae, from a purely density- based effect to a density- and trait-based effect. Individuals in a population differ, and it is upon the variation of traits of individuals that selective processes act (McCormick 1998). The combined effects of density- and trait-mediated effects may be represented as a map plotting the 'state' of a species in terms of abundance and the value of a relevant trait. Changes in 'state' occur as a consequence of different levels of environmental stress. Some of these states are represented in Fig. 1: an increase in environmental stress moves the species from a state of high quality and abundance to different states; density-mediated effects lead to the species moving along a vertical line, while trait-mediated effects lead to movement along a horizontal line. Since at high stress, abundance should decrease, pure trait-mediated effects should only be observed when comparing sites with low vs. sites with intermediate stress, but they may also be present in sites with high stress. Delayed effects on population abundance arise if the trait-mediated effects represented in the diagram propagate to the next life phase and affect subsequent survival or reproduction.

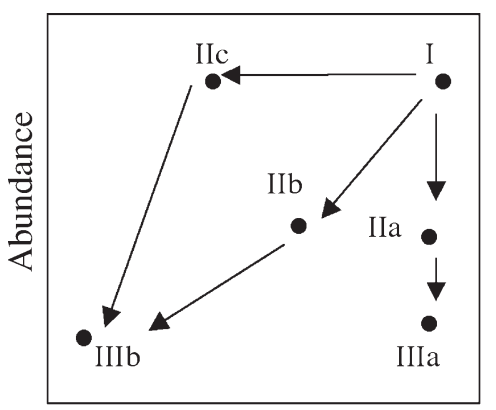

Environmental stress:

$\begin{array}{ll}\text { I } & \text { Low } \\ \text { II } & \text { Intermediate } \\ \text { III } & \text { High }\end{array}$

Trait value

Fig. 1. Diagram of trait values and abundance of a species as dependent on the level of environmental stress. At low stress, abundance and quality (trait value) of individuals are high (State I); an increase in stress leads to different potential responses (States IIa, IIb, and IIc), and further increase leads to a reduction of abundance without (IIIa) or with (IIIb) changes in the value of the trait. Mass-action processes model the path Ia-IIa-IIIa; the inclusion of traits of individuals allows for additional responses. Changes in traits may become manifest in subsequent stages or phases (DELPHIs) as changes in mortality
Evidence of DELPHIs comes mostly from laboratory studies, but also from a few field studies (e.g. Miron et al. 2000, Phillips 2002, Jarrett 2003). Most studies are focused on how larval or hatchling quality influence juvenile growth (Pechenik et al. 1998, Giménez et al. 2004), survival (Moran \& Emlet 2001, Phillips 2002, Marshall \& Keough 2003) or adult reproduction (Wendt 1998, Marshall et al. 2003). DELPHIs may involve a negative effect due to stressful conditions (e.g. low energy reserves due to food limitation) or adaptive plastic responses (e.g. acclimation, changes in shape). Examples of negative trait-mediated effects are, for instance, effects in the size or growth of juveniles due to a delay in metamorphosis (Hunt \& Scheibling 1997, Pechenik et al. 1998, Gebauer et al. 2003) or food conditions (Pechenik 1996a,b, Phillips 2002). For instance, Phillips (2002) showed that the loss of juvenile mussels in the field was higher for those that had been raised in lower food conditions. A more complex effect was found in the estuarine crab Chasmagnathus granulata: under food or salinity stress, the larvae follow a longer developmental pathway, but the surviving megalopae are larger (Giménez \& Torres 2002). Larger megalopae originated larger juveniles that survived longer under food and salinity stress (Giménez et al. 2004).

In addition, DELPHIs may also occur as maternal effects (George 1999, Qiu \& Qian 1999, Marshall \& Keough 2004, Paschke et al. 2004) or from embryonic to larval stages. For instance, Rosenberg \& Costlow (1979), Laughlin \& French (1989), Giménez \& Anger (2003) showed that larval tolerance to salinity in 2 estuarine crabs depends on the salinity experienced by embryos; thus, larvae released by females living in different environmental conditions may be in different 'acclimation states'. Furthermore, in the estuarine crab Chasmagnathus granulata, larval survival depends on the interaction between egg biomass and environmental conditions experienced by embryos and larvae (Giménez 2002, Giménez \& Anger 2003).

Laboratory experiments allow the evaluation of DELPHIs through at least a great part of the life cycle of a species, although this has been done in only a few cases (e.g. the barnacle Balanus amphitrite: Qiu \& Qian 1999; the bryozoan Bugula neritina: Marshall et al. 2003, Marshall \& Keough 2004; the crab Chasmagnathus granulata: Giménez et al. 2004).

The important point, largely unexplored, is how strong DELPHIs are. They may be significant components of early post-settlement mortality, which is high in marine invertebrates (Hunt \& Scheibling 1997). Their importance may depend on the existence of physiological thresholds at metamorphosis. For instance, changes in larval physiological condition may lead to mortality at metamorphosis, depending on 
a minimum threshold (e.g. see Jarrett 2003), thus reducing the range of variability in quality of juveniles: a high threshold should strongly reduce DELPHIs. On the other hand, pelagic environmental conditions affect size at settlement through switches in developmental pathways (see Giménez et al. 2004); they increase the range of variation of a juvenile character, potentially increasing DELPHIs. The importance of DELPHIs may be scale-dependent, as in other pre-settlement processes. Menge et al. $(1997,2003)$ showed that growth rate of benthic organisms may be affected by meso-scale patterns in distribution of nutrients in the adjacent coast. This may be a key spatial scale at which DELPHIs are important, since natural variability in food in the plankton may lead to variability in the traits of settlers. Pineda et al. (2002) and Jarrett (2003) showed that size, energy content, survival, and growth rates of Semibalanus balanoides vary considerably within a settlement season. Thus, DELPHIs may be important at least on a time scale smaller than the period of settlement season.

\section{COMBINED EFFECTS OF DEMPHS AND DELPHIS ON THE SETTLEMENT-STOCK FUNCTION}

The role of pre- and post-settlement processes has usually been evaluated through the settlementstock (settler-adult relationships), settler-recruit or recruit-stock functions (Caley et al. 1996, Hunt \& Scheibling 1997, Menge 2000). These functions may arise from a survey or from an experiment where a factor is manipulated and the change in the correlation is studied. The difference between settlement-stock and recruit-stock functions is that, in the latter, recruitment includes early post-settlement mortality. Recruitment will reflect settlement only if mortality between settlement and recruitment is density-independent or weakly density-dependent (Connell 1985, Holm 1990) and consequently the recruit-stock function should resemble the settlement-stock function. In this case there is evidence for an effect of settlement rate on recruitment or on the benthic population. For instance, Eggleston \& Armstrong (1995) and Luppi et al. (2002) found evidence for strong cannibalism during the early juvenile stages of estuarine crabs. In the crab Cancer magister (Eggleston \& Armstrong 1995) initial differences in abundance of megalopae were not reflected in the abundance of juveniles. A significant regression between settlers and recruits was found only in experimental plots where juveniles were protected from predation or cannibalism. Thus, only under protection from strong density-dependent predation and cannibalism will the recruit-stock function resemble the settler-stock function.
Caley et al. (1996) summarized 4 possible scenarios for the stock-recruitment function as a consequence of recruitment and post-recruitment processes. Thus, it is possible to define scenarios for a settlement-stock function as a consequence of pre- and post-settlement processes. But how are trait- and density-mediated effects interacting in the settlement-stock function? If DELPHIs affect survival, then any pattern of mortality should not be solely interpreted as a consequence of a post-settlement process. The introduction of DELPHIs allows for different scenarios (Fig. 3):

Scenario 1. Post-settlement processes do not counterbalance the settlement signal. This scenario resembles all 4 cases in Caley et al. (1996).

1a. Lack of correlation between trait-mediated survival and settlement rate: Trait-related survival is randomly distributed across different densities of recruits, affecting the scattering of data around the predicted settlement-stock function. This situation may be interpreted as Cases 2 and 3 in Caley et al. (1996).

1b. The survival rate due to the quality of settlers correlates positively with settlement rate: Higher mortality after settlement occurs in places with lower settlement rate. This may occur when a pelagic factor (e.g. food availablility) affects abundance as well as the quality of larvae, so that increasing stress leads to fewer lower quality larvae settling at some sites. In this case, the shape of the settlement-stock function will reflect the density-mediated relationship reinforced by the trait-mediated relationship.

1c. The survival rate due to the quality of settlers correlates negatively with settlement rate: Higher mortality after settlement occurs in places with higher settlement rate. At least 2 potential cases may explain this pattern: (i) negative correlations between factors affecting quality of larvae (e.g. food availability) and settlement rates (e.g. transport by currents), and (ii) competition for food in the pelagic environment reducing larval quality but not abundance. Here, the settlement-stock function arising from density-mediated effects will be compensated by the trait-mediated effect of the opposite sign, leading (in extreme situations) to a non-significant correlation between the numbers of settlers and recruits. Such a situation is more likely to arise if there is some density-dependent post-settlement mortality, as in Cases 3 and 4 in Caley et al. (1996). The interesting corollary here is that the lack of correlation may be interpreted as evidence for strong density-dependent post-settlement factors, although it was the trait-mediated pre-settlement effect that caused the lack of correlation.

Scenario 2. Negative post-settlement effects counterbalance the stock-recruit function. This is Case 4 in Caley et al. (1996), but with a strong negative density-dependent process. An interesting aspect is how 


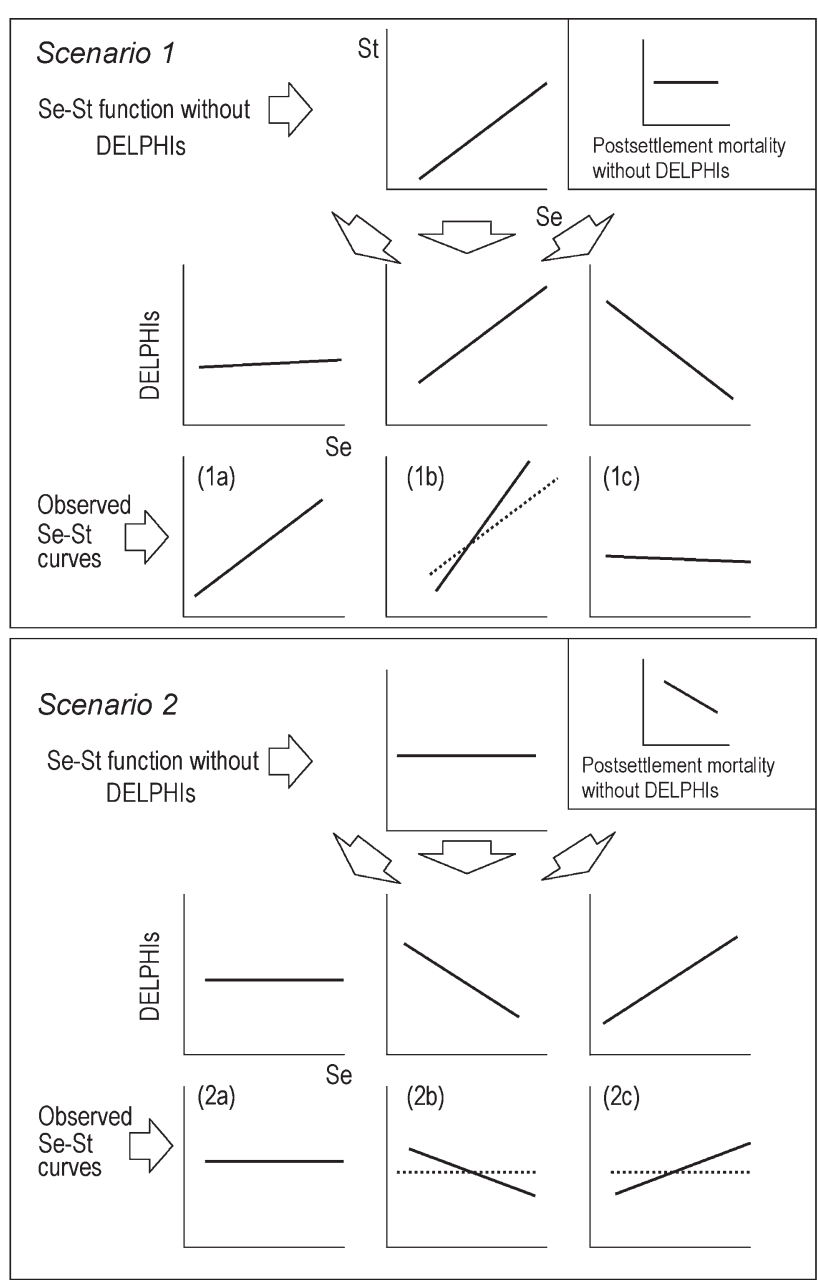

Fig. 2. Scenarios for the settlement-stock (Se-St) function originating from the interaction of pre- and post-settlement processes, without and with different patterns of trait-mediated survival (DELPHIs). The graphs at upper right show post-settlement mortality as a function of abundance. Hatched lines: expected Se-St function without DELPHIs. Scenario 3 is not included

DELPHIs interact with density-dependent post-settlement processes. The fact that trait-mediated effects are propagated to the benthic phase allows for an interaction of the pre- and post-settlement process. In this case the effect of trait-mediated pre-settlement processes is context-dependent, being the context given by the post-settlement conditions.

2a. A process causes density-dependent mortality, but it affects settlers of different quality in the same way: For instance, desiccation, wave action, or predation may release space, but a limited number of refuges are occupied by setters irrespective of their quality. At low densities, mortality is low, since most individuals occupy the refuges; at high densities mortality is high, since many individuals settled outside of the refuges. In this case the settlement-stock function is a flat curve, because post-settlement mortality is positively correlated with density, with DELPHIs affecting the scatter of points. If competition leads to mortality, the DELPHIs may lead to an increase in space, relaxing competition and lengthening the life expectancy of high quality settlers. The amount of the space made available will depend on the spatial distribution of settlers of different qualities.

2b. A process causes density-dependent mortality, and its effect is exacerbated by individual quality: For instance, at sites with limited periods of lack of food or moderate food stress, settlers with higher nutritional reserves or greater size may survive better, since they have a higher tolerance to short periods of starvation or easier access to limited resources. Likewise, under moderate levels of wave action, the survival rate may vary with the size of settlers, due to size-related differences in tensile strength. Predators may select or reject larger settlers; larger settlers may escape from predators more frequently due to higher speed or better defences. Settlers of higher quality may colonize the limited refuges from desiccation, so that settlers at the sites with high settlement rates, outside of the refuges, suffer a synergistic effect of desiccation and low quality. In all of these cases, a synergistic effect exaggerates the signal of post-settlement processes in the settlement-stock function.

2c. Post-settlement survival is negatively densitydependent, but DELPHI survival depends on positive effects: Post-settlement mortality is negatively densitydependent, but DELPHI mortality depends on positive effects. In the settlement-stock function, positive postsettlement effects may actually be interpreted as a signal of pre-settlement processes. Here there may be a compensation effect that leads to a significant settlement-stock function.

Scenario 3. Positive post-settlement effects are present. These are not very well studied, although models about the influence of positive density-dependent process on benthic communities have been proposed (Bruno \& Bertness 2001). Positive post-settlement effects may be common in soft sediments (Peterson \& Black 1993), but they also occur in hard substrata (Bertness \& Leonard 1997, Kawai \& Tokeshi 2004). Ignoring any effect of DELPHIs, a positive post-settlement effect may increase the slope of the settlementstock function, leading perhaps to the false conclusion that there is a large influence of pre-settlement processes on the community. If there is no correlation between DELPHIs and post-settlement processes producing positive effects, DELPHIs will affect the scatter of points in the stock-recruitment function (Scenario 3a). If there is a positive correlation, the effects of these post-settlement processes on the settlement-stock 
function will be exacerbated by the DELPHIs (Scenario $3 b)$; if there is a negative correlation the effects will be attenuated (Scenario 3c).

\section{CONCLUDING REMARKS}

In the definition of the scenarios, I used a dichotomous approach (low vs. high density-dependent postsettlement mortality) with a linear relationship in the settlement-stock function. This may be viewed as an oversimplification. For instance, any of the interactions described in Scenarios 2 and 3 may apply to Scenario 1 under 'weak' density-dependence. Moreover, the settlement-stock or settler-recruit functions may be the consequence of non-linear post-settlement processes (e.g. Pile et al. 1996) or DELPHIs. However, I wanted to describe the potential effects of DELHIs by using simple examples. I described a few of of the many potential outcomes of the settlement-stock function. Obviously, some scenarios are more plausible than others. For instance, Scenario 2b may occur more frequently than Scenario 2c, since an occurrence of positive effects should affect both DELPHI and post-settlement survival.

In the above cases, experimental manipulation of the post-settlement process cannot discriminate between trait-mediated or other phenotypic effects and the manipulated process. If the survival resulting from differences in quality of settlers is not correlated with settlement rate (Scenario 1a) and does not depend on any post-settlement processes (Scenario 2a), differences in quality of settlers will most likely affect the scatter of the points around the settlement-stock function. Otherwise, false conclusions will be made with regard to the processes that explain adult abundance. To evaluate the potential role of DELPHIs in stock-settlement studies, we need a measure of the quality of settling larvae and juveniles just after settlement, such as initial size, biomass or chemical content of settlers, as these should reflect the environmental conditions experienced by the larvae. Non-invasive measurements such as size may be preferable, since they make it possible to monitor the quality and fate of individuals over time, at least in sessile species. Although invasive measures (e.g. chemical parameters) do not allow for the fate of individuals to be followed, they may better reflect their physiological state, and they may be obtained by subsampling. Combining both types of measures may make it possible to evaluate whether among-cohort variability in early post-settlement mortality is correlated with among-cohort variability in initial quality of individuals. Experiments on the role of predation or competition in structuring communties may also include the individual variability of settlers, as has been done for benthic fishes (McCormick \& Hoey 2004).

Benthic community ecology is changing (Roughgarden 1998). Whether this change involves a 'Kuhnian revolution' or not (see discussions in Graham \& Dayton 2002, Paine 2002), an important contribution to that change is the set of re-evaluations in perspective owed to 'recent interest in the long-realized consequences of variations in recruitment' (Underwood \& Fairweather 1988). The incorporation of studies of larval transport, survival and settlement should lead to a more complete theory of marine communities, through the fusion of aspects of physical oceanography with 'classical' community ecology (Alexander \& Roughgarden 1996, Menge et al. 1997, Connolly \& Roughgarden 1998), and through the introduction of a concept of scale (Levin 1992). However, this approach should not lead to a shift of attention between pre- or post-settlement factors. Perhaps, dichotomous approaches like 'pre- vs. post-settlement' or 'density vs. trait-mediated' should be avoided in favour of studies incorporating the combined role of individual variability, supply of larvae, and post-settlement processes. Thus, future studies should include trait-mediated effects, i.e. DELPHIs and TMII, which cascade through the food web. They both operate on the potential for phenotypic plasticity: their importance depends on how plastic the phenotype is. Recent studies have shown that TMII can exert strong quantitative effects on benthic communities, and this calls for more research on DELPHIs.

Acknowledgements. This manuscript benefited from comments and suggestions by Dr. K. Anger, G. Torres and 3 anonymous reviewers. Financial support was given by the Alexander-von-Humboldt-Stiftung.

\section{LITERATURE CITED}

Abrams P (1995) Implications of dynamically variable traits for identifying, classifying and measuring direct and indirect effects in ecological communities. Am Nat 146: $112-134$

Alexander S, Roughgarden J (1996) Larval transport and population dynamics of intertidal barnacles: a coupled benthic/oceanic model. Ecol Monogr 66:259-275

André C, Rosenberg R (1991) Adult-larval interactions in the suspension-feeding bivalves Cerastoderma edule and Mya arenaia. Mar Ecol Prog Ser 71:227-234

Beckerman A, Benton T, Ranta E, Kaitala V, Lundberg P (2002) Population dynamic consequences of delayed lifehistory effects. Trends Ecol Evol 17:263-269

Bertness M, Leonard G (1997) The role of positive interaction in communities: lessons from intertidal habitats. Ecology 78:1976-1989

Bruno J, Bertness M (2001) Habitat modification and facilitation in benthic marine communities. In: Bertness $M$, Gaines S, Hay M (eds) Marine community ecology. Sinauer Associates, Sunderland, MA, p 201-215

Caley M, Carr M, Hixon M, Hughes T, Jones G, Menge B 
(1996) Recruitment and local dynamics of open marine populations. Annu Rev Ecol Syst 27:477-500

Connell J (1961) The influence of interespecific competition and other factors on the distribution of barnacle Chtamalus stellatus. Ecology 42:710-723

Connell J (1985) The consequence of variation in initial settlement vs. post-settlement mortality in rocky intertidal communities. J Exp Mar Biol Ecol 93:11-45

Connolly S, Roughgarden J (1998) A latitudinal gradient in north-eastern Pacific intertidal community structure: evidence for an oceanographically based synthesis of marine community theory. Am Nat 151:312-326

Connolly S, Roughgarden J (2003) Theory of marine communities: competition, predation, and recruitment-dependent interaction strength. Ecol Monogr 69:277-296

Connolly S, Menge B, Roughgarden J (2001) A latitudinal gradient in recruitment of intertidal invertebrates in the northeast Pacific Ocean. Ecology 82:1799-1813

Eggleston D, Armstrong D (1995) Pre- and post-settlement determinants of estuarine Dungeness crab recruitment. Ecol Monogr 65:193-216

Fairweather P (1988) Consequences of supply-side ecology: manipulating the recruitment of intertidal barnacles affects the intensity of predation upon them. Biol Bull (Woods Hole) 175:349-354

Gaines S, Roughgarden J (1985) Larval settlement rate: a leading determinant of structure in an ecological community of the marine intertidal zone. Proc Natl Acad Sci USA 82:3707-3711

Gebauer P, Paschke K, Anger K (2003) Delayed metamorphosis in decapod crustaceans: evidence and consequences. Rev Chil Hist Nat 76:169-175

George S (1999) Egg quality, larval growth and phenotypic plasticity in a forcipulate seastar. J Exp Mar Biol Ecol 237: 203-224

Giménez L (2002) Effects of prehatching salinity and initial larval biomass on survival and duration of development in the zoea 1 of the estuarine crab, Chasmagnathus granulata, under nutritional stress. J Exp Mar Biol Ecol 270: 93-110

Giménez L, Anger K (2003) Larval performance in an estuarine crab, Chasmagnathus granulata, is a consequence of both larval and embryonic experience. Mar Ecol Prog Ser 249:251-264

Giménez L, Torres G (2002). Larval growth in the estuarine crab Chasmagnathus granulata: the importance of salinity experienced during embryonic development, and the initial larval biomass. Mar Biol 141:877-885

Giménez L, Anger K, Torres G (2004) Linking life history traits in successive phases of a complex life cycle: effects of larval biomass on early juvenile development in an estuarine crab, Chasmagnathus granulata. Oikos 104: $570-580$

Graham M, Dayton P (2002) On the evolution of ecological ideas: paradigms and scientific progress. Ecology 83: 1481-1489

Harms J, Anger K (1989) Settlement of the barnacle Eliminius modestus Darwin on test panels at Helgoland (North Sea): a ten year study. Sci Mar 53:417-421

Highsmith R (1982) Induced settlement and metamorphosis of sand dollar (Dendraster excentricus) larvae in predatorfree sites: adult sand dollar beds. Ecology 63:329-337

Holm E (1990) Effects of density dependent mortality on the relationship between recruitment and larval settlement. Mar Ecol Prog Ser 60:141-146

Hunt H, Scheibling R (1997) Role of early post-settlement mortality in recruitment of benthic marine invertebrates.
Mar Ecol Prog Ser 155:269-301

Hyder K, Johnson M, Hawkins S, Gurney W (1998) Barnacle demography: evidence for an existing model and spatial scales of variation. Mar Ecol Prog Ser 174:89-99

Jarrett J (2003) Seasonal variation in larval condition and post-settlement performance of the barnacle Semibalanus balanoides. Ecology 84:384-390

Jeffery C (2003) Determination of abundance and distribution of an intertidal barnacle: settlement or post-settlement mortality? Mar Ecol Prog Ser 246:291-305

Karlson R, Levitan D (1990) Recruitment-limitation in open populations of Diadema antillarum: an evaluation. Oecologia 82:40-44

Kawai T, Tokeshi M (2004) Variable modes of facilitation in the upper intertidal: goose barnacles and mussels. Mar Ecol Prog Ser 272:203-213

Keough M, Downes B (1982) Recruitment of marine invertebrates: the role of active larval choices and early mortality. Oecologia 54:348-352

Laughlin R, French W (1989) Interactions between temperature and salinity during brooding on subsequent zoeal development of the mud crab Rhithropanopeus harrisii. Mar Biol 102:377-386

Levin S (1992) The problem of pattern and scale in ecology. Ecology 73:1943-1767

Luppi T, Spivak E, Anger K, Valero J (2002) Patterns and processes of Chasmagnathus granulata and Cyrtograpsus angulatus (Brachyura: Grapsidae) recruitment in Mar Chiquita Coastal Lagoon, Argentina. Estuar Coast Shelf Sci 55:287-297

Marshall D, Keough M (2003) Effects of settler size and density on early post-settlement survival of Ciona intestinalis in the field. Mar Ecol Prog Ser 259:139-144

Marshall D, Bolton T, Keough M (2003) Offspring size affects the post-metamorphic performance of a colonial invertebrate. Ecology 84:3131-3137

McCormick M (1998) Condition and growth of reef fish at settlement: is it important? Aust J Ecol 23:258-264

McCormick M, Hoey A (2004) Larval growth history determines juvenile growth and survival in a tropical marine fish. Oikos 106:225-242

Menge B (2000) Recruitment vs. post-recruitment processes as determinants of barnacle population abundance. Ecol Monogr 70:265-288

Menge B, Sutherland J (1987) Community regulation: variation in disturbance, competition, and predation in relation to environmental stress and recruitment. Am Nat 130: $730-757$

Menge B, Daley B, Wheeler P, Dahlhoff E, Sanford E, Strub P (1997) Benthic-pelagic links and rocky intertidal communities: bottom-up effects on top-down control? Proc Natl Acad Sci USA 94:14530-14535

Menge B, Lubchenco J, Bracken M, Chan F and 9 others (2003) Coastal oceanography sets the pace of rocky intertidal community dynamics. Proc Natl Acad Sci USA 100: 12229-12234

Miron G, Walters L, Tremblay R, Bourget E (2000) Physiological condition and barnacle larval behaviour: a preliminary look at the relationship between TAG/DNA ratio and larval substratum exploration in Balanus amphitrite. Mar Ecol Prog Ser 198:303-310

Moran A, Emlet R (2001) Offspring size and performance in variable environments: field studies on a marine snail. Ecology 82:1597-1612. 2001

Olaffson E, Peterson C, Ambrose W (1994) Does recruitment limitation structure populations and communities of macro-invertebrates in marine soft sediments: the relative 
significance of pre- and post-settlement processes. Oceanogr Mar Biol Annu Rev 32:65-109

Paine R (2002) Advances in ecological understanding: by Kuhnian revolution or conceptual evolution? Ecology 83: 1553-1559

Paschke K, Gebauer P, Buchholz F, Anger K (2004). Seasonal variations in starvation resistance of early larval North Sea shrimp Crangon crangon (Decapoda: Crangonidae). Mar Ecol Prog Ser 279:183-191

Pechenik J, Estrella M, Hammer K (1996a) Food limitation stimulates metamorphosis of competent larvae and alters post-metamorphic growth rate in the marine prosobranch gastropod Crepidula fornicata. Mar Biol 127:267-275

Pechenik J, Hammer K, Weise C (1996b) The effect of starvation on acquisition of competence and post-metamorphic performance in the marine prosobranch gastropod Crepidula fornicata (L.). J Exp Mar Biol Ecol 199:137-152

Pechenik J, Wendt D, Jarrett J (1998) Metamorphosis is not a new beginning. BioScience 48:901-910

Peterson C, Black R (1993) Experimental tests of the advantages and disadvantages of high density for 2 coexisting cockles in a Southern Ocean lagoon. J Anim Ecol 63: $614-633$

Phillips N (2002) Effects of nutrition-mediated larval condition on juvenile performance in a marine mussel. Ecology 83: 2562-2574

Pile A, Lipcius R, van Montfrans J, Orth R (1996) Densitydependent settler-recruit-juvenile relationships in blue crabs. Ecol Monogr 66:277-300

Pineda J (2000) Linking larval settlement to larval transport: assumptions, potentials, and pitfalls. Oceanogr East Pac 1: $61-81$

Pineda J, Riebensahm D, Medeiros-Bergen D (2002) Semibalanus balanoides in winter and spring: larval concentration, settlement, and substrate occupancy. Mar Biol 140: 789-800

Qiu J, Qian P (1999) Tolerance of the barnacle Balanus amphitrite amphitrite to salinity and temperature stress: effects of previous experience. Mar Ecol Prog Ser 188:123-132

Raimondi P (1990) Patterns, mechanisms, consequences of

Editorial responsibility: Otto Kinne (Editor),

Oldendorf/Luhe, Germany variability in settlement and recruitment of an intertidal barnacle. Ecol Monogr 60:283-309

Raimondi P, Forde S, Delph L, Lively C (2000) Processes structuring communities: evidence for trait-mediated indirect effects through induced polymorphisms. Oikos 91:353-361

Robles C (1997) Changing recruitment in constant species assemblages: implications for predation theory in intertidal communities. Ecology 78:1400-1414

Rosenberg R, Costlow J (1979) Delayed response to irreversible non-genetic adaptation to salinity in early development of the brachyuran crab Rhithropanopeus harrisii, and some notes on adaptation to temperature. Ophelia 18: $7-112$

Roughgarden J (1986) A comparison of food limited and space limited animal competition communities. In: Diamond J, Case $\mathrm{T}$ (eds) Community ecology. Harper \& Row, New York, p 492-516

Roughgarden J (1998) How to manage fisheries. Ecol Appl 8S: 160-164

Roughgarden J, Gaines S, Possingham H (1988) Recruitment dynamics in complex life cycles. Science 241:1460-2466

Schmitz O, Krivan V, Ovadia O (2004) Trophic cascades: the primacy of trait-mediated indirect interactions. Ecol Lett 7: 153-163

Trussell G, Ewanchuk P, Bertness M (2002) Field evidence of trait-mediated indirect interactions in a rocky intertidal food web. Ecol Lett 5:241-245

Underwood A, Fairweather P (1989) Supply-side ecology and benthic marine assemblages. Trends Ecol Evol 4:16-20

Wendt D (1998) Effect of larval swimming duration on growth and reproduction of Bugula neritina (Bryozoa) under field conditions. Biol Bull (Woods Hole) 195:126-135

Werner E, Peacor S (2003). A review of trait-mediated indirect interactions in ecological communities. Ecology 84: $1083-1100$

Wilson W (1991) Competition and predation in marine softsediment communities. Annu Rev Ecol Syst 21:221-241

Woodin S (1976) Adult-larval interactions in a dense infaunal assemblages: patterns of abundance. J Mar Res 34: 25-41

Submitted: June 2, 2004; Accepted: September 16, 2004 Proofs received from author(s): November 11, 2004 